gations: haemoglobin $7.6 \mathrm{~g} / 100 \mathrm{ml}$, white cell count $18,000 / \mathrm{mm}^{3}$, and a negative sickling test.

A diagnosis of late pyomyositis was made and after 24 hours treatment with penicillin and streptomycin the thigh was drained under general anaesthesia, and obviously necrotic skin was excised. Wound swabs yielded a mixed growth of coliforms, but acid-fast bacilli were not sought at this stage.

In spite of apparently free drainage from the leg, appropriate antibiotics, piecemeal excision of more necrotic skin, and transfusion of one unit of blood, the child remained very ill three weeks after admission. Re-examination under general anaesthesia showed that the ulcer on the thigh now extended over $3 \%$ of the body surface and the lateral edge only was adherent to underlying granulations. Elsewhere the ulcer margin was undermined $6 \mathrm{~cm}$ towards the groin and up to $12 \mathrm{~cm}$ distally, lifting the skin off the patella and linking the main ulcer in the thigh with smaller ulcers either side of the tibial tubercle. Thick plaques of gritty necrotic fat were excised from under the skin flaps and much cheesy debris was wiped out of the large cavity. A biopsy of skin and subcutaneous tissue was taken from the superior limit of the lesion. Even at this unsuitable site the histology was typical of Buruli ulcer, and clusters of acid-fast bacilli were seen in Ziehl-Neelsen stained sections. An attempt to culture Mycobacterium ulcerans from necrotic fat was not successful.

During the week after operation the child lost her fever and began to eat, and she was cheerful and pain free for the first time. The discharge from the ulcer lessened and the undermined edges begarı to stick down to healthy granulations. Skin grafting was performed four weeks after débridement, but was only partially successful. The need for more aggressive excision was not appreciated until the remaining ulcer showed signs of renewed activity, but further débridement and skin grafting eventually secured healing.

This child was admitted with extensive disease which probably corresponds to the "fulminating" lesion described by the Uganda Buruli Group. ${ }^{2}$ Ulceration had only just started but severe secondary infection was already well established. She was in pain and very ill, features which are rare in uncomplicated Mycobacterium ulcerans infection, and this diagnosis was not considered until the ulcer continued to enlarge in spite of apparently adequate treatment. It is interesting to note that fever and malaise persisted until most of the necrotic debris had been removed from the leg, but thereafter the child was well and lively throughout the weeks of treatment needed to secure healing of her ulcer

In Uganda cases of Buruli ulceration cluster round tributaries of the Nile flowing through marshy ground. One woman with a probable Buruli ulcer lived in the same village as the patient and used the same water supply, and a second woman with a suspicious ulcer lived near the mouth of this river. A third patient, a child with a large ulcer on her elbow, lived near a second river which, like the Densu, flows across the Accra plains within 50 miles $(80 \mathrm{~km})$ of the capital. It seems possible that a reservoir of infection exists in relation to these two rivers and that more cases will be recognized in this area.-I am, etc.,

\section{Colchester, Essex}

AnNe C. Bayley

1 MacCallum, P., Tolhurst, J. C., Buckle, G., and Sissons, H. A., Fournal of Pathology and Bac-
teriology, 1948, 60, 93. 2 Uganda Buruli Group, British Medical fournal, $1970,2,390$.

\section{Use and Abuse of Thyroidectomy}

SIR,-We should like to comment on your recent leading article (20 March, p. 619) on the use and abuse of thyroidectomy for thyrotoxicosis, in which you deal principally with the sequelae of operation for thyroid cancer. While by and large we agree that the recurrent laryngeal nerves are at particular risk in operation on the undifferentiated anaplastic tumour, we would mention the advantages of surgery following deep $x$-ray therapy. The gland is greatly reduced in size and relatively avascular, and unless infiltrated by cancer the recurrent laryngeal nerve may be less at risk by using a special technique of pledget dissection.

But we cannot accept your statement that the morbidity of "hypoparathyroidism" is related to interference with the parathyroids or their blood supply. Postoperative hypocalcaemia seldom follows thyroidectomy for non-toxic goitre even where resection has been radical. ${ }^{2}$ In another context hypocalcaemia is unusual in patients (excluding those with overt bone disease) subjected to removal of a parathyroid adenoma and in whom biopsy of the remaining parathyroids has been carried out. In contrast postoperative hypocalcaemia is not uncommon following thyroidectomy for thyrotoxicosis particularly in the young, previously severely thyrotoxic patient who has been left with a small remnant. Here there is good evidence to link the hypocalcaemia with thyrotoxic osteodystrophy, which is generally manifest preoperatively by raised levels of serum alkaline phosphatase. Hypocalcaemia and related symptoms are generally transient and cease with calcium repletion within the hungry bones.

It is now doubtful if Fourman's ${ }^{3}$ thesis of partial parathyroid insufficiency has real validity and several reports and controlled trials $^{1-7}$ have failed to substantiate his findings. Indeed, while accepting that hypocalcaemia, albeit as a rule of temporary nature may follow ablative surgery for thyroid cancer, it is now considered that the term "hypoparathyroidism", when used for hypocalcaemia developing within one or two days of thyroidectomy for thyrotoxicosis, is misleading and should be discarded.-We are, etc.,

W. MiChIE J. M. STOWERS

C. A. S. PEgG

P. D. BEWSHER

Roval Infirmary of Aberdeen,

Aberdeen

1 Michie W., et al., Lancet, 1971, 1, 508 Murley, R. S., and Peters, P. M., Proceeding of the Roval Society of Medicine, 1961, 54, 487.
Davis, R. H., Fourman, P., and Smith, J. W. G. Davis, R. H., Fourman, P., and Smith, J. W. G.,
Lancet, 1961, 2, 1432. Michie, W., Stowers, J. M., Frazer, S. C., and
Gunn, A., British fournal of Surgery, 1965,
52, 503.

6 Rose, N., Lancet, 1963, 2, 116. G. E., Irish Fournal of Medical Science, 1967, $7 \begin{gathered}\text { Stowers, J. M., Michie, W., and Frazer, S. C., } \\ \text { Lancet, 1967, 1, 124. }\end{gathered}$

\section{Ulcerative Colitis and \\ Rectal Carcinoma}

SIR,-In his interesting article (24 April, p. 203) Mr. S. Aylett claims that the risk of cancer arising in the retained rectal stump after colectomy and ileorectal anastomosis for ulcerative colitis is relatively slight because such growths developed in only $2 \%$ of the
350 surviving patients on whom he had performed this operation between 1952 and 1968 inclusive. To many people, however, an incidence of even one case in 50 may not seem insignificant. Moreover, this bald statement of frequency almost certainly underestimates the continued capacity of the diseased rectal stump in these cases to produce malignant tumours. As is well known, the predisposition to large bowel cancer in ulcerative colitis is a cumulative process, increasing year by year, ${ }^{1}$ and it may not be for $10-15$ years after colectomy and ileorectal anastomosis that the diseased stump of rectum begins to reveal its true malignant potential. Thus no less than four of the carcinomas in Mr. Aylett's cases arose in the 29 patients who had their operations performed during the years 1952-55, the incidence of rectal cancer in this group, who were all followed up at least 15 years after operation, being accordingly of the order of $14^{\prime \prime}$.. We would anticipate, therefore, that when all his patients have been followed up for a similar period of time, Mr. Aylett may have many more rectal carcinomas to report.

Operation for colitis is most often undertaken in adolescence or early adulthood, and these young patients may nowadays reasonably expect to enjoy several decades of life after successful surgical treatment. Mr. Aylett's long-term data unfortunately do little to dispel the nagging fear that, if their operation takes the form of a colectomy and ileorectal anastomosis instead of the more usual complete proctocolectomy and ileostomy, they may be exposed to a serious risk of developing rectal cancer. It seems to us, therefore, that whatever may be the immediate advantages of this operative techniqueand we would not deny that in some cases they may be considerable-the surgeon who elects to use it in the treatment of ulcerative colitis assumes a grave responsibility in leaving his patients inadequately protected against the risk of subsequent malignant disease. True, there are some hopes that it may be possible by means of rectal biopsy to select patients specially liable to produce colitis carcinomas, 2 but no one could pretend that the reliability of this method is as yet anything like established.-We are, etc.,

J. C. Goliginer F. T. DE DOMBAL

University Department of Surgery,

General Infirmary.

Leeds.

de Dombal, F. T., Watts, J. McK., Watkinson. G., and Goligher, J. C., British Medical fournal, 1966, 1. 1332.

Morson, B. C., and Pang, L. S. C., Gut, 1967 8, 423.

\section{Encouraging Recruits in Medicine}

SIR,-I feel I must add my twopenceworth to your columns on the subject of medical students' remuneration (3 April, p. 51, and 17 April, p. 17). I have just finished working for three years for the Medical Research Council, where my salary was almost $£ 2,000$ p.a. I have now returned to medical school to complete the clinical course on a grant of $\$ 314$ p.a. I certainly do not consider I am making a "sacrifice"-on the contrary, I think I am very lucky.

In my naïveté $I$ am astonished at the attitudes evinced by some of your student correspondents, and in conversations I have had in my own medical school. A small pro- 